\title{
Observational study on clinicopathological profile of thrombocytopenia cases in a medical college hospital
}

\author{
Kumar A. ${ }^{1}$, Priyadarshi A. ${ }^{2}$, Kumar S. ${ }^{3}$, Kumar L.P. ${ }^{4}$ \\ ${ }^{1}$ Dr. Ajay Kumar, Associate Professor, ${ }^{2}$ Dr. Avinash Priyadarshi, Assistant Professor, ${ }^{3}$ Dr. Sanjay Kumar, Professor, \\ Department of Pathology, Mata Gujri Memorial Medical College and Lions Seva Kendra Hospital, Kishanganj, Bihar, \\ ${ }^{4}$ Dr. Prabhat Kumar Lal, Associate Professor, Department of PSM, Darbhanga Medical College, Darbhanga, Bihar, India
}

Corresponding Author: Dr. Avinash Priyadarshi, Assistant Professor, Department of Pathology, Mata Gujri Memorial Medical College and Lions Seva Kendra Hospital, Kishanganj, Bihar, India. E-mail- avinashpriyadarshi17@gmail.com

\begin{abstract}
Introduction: Thrombocytopenia is a commonly encountered condition with varying aetiologies ranging from infective to chronic conditions and malignancies. Knowledge of causes and pattern of disease is helpful in management of cases. Aims \& objectives: The present study was conducted to assess the causes, clinical profile and findings of laboratory investigations of patients suffering from thrombocytopenia. Material \& Methods: The present cross-sectional hospitalbased study was conducted upon 99 patients suffering from thrombocytopenia. Detailed clinical history, physical examination and reports of laboratory investigations were noted. Results: $34.3 \%$ patients belonged to the age group of 21-30 years. $57.6 \%$ of them were males. Thrombocytopenia was mild $(1,00,000-1,50,000)$ in $24.2 \%$ patients, moderate $(50,000-1,00,000)$ in $52.5 \%$ and severe $(<50,000)$ in $23.2 \%$. Dengue accounted for $31.3 \%$ cases, malaria for $16.2 \%$, enteric fever for $7.1 \%$ and septicaemia for 3\%. Megaloblastic anaemia was responsible in 24.2\% cases. Most common site for bleeding was skin and mucous membrane where bleeding manifested in the form of petechiae, purpura and ecchymosis (18.2\%). Conclusion: Knowledge of causes and pattern of disease is helpful in management of cases.
\end{abstract}

Keywords: Observational Study, Platelet Count, Thrombocytopenia

\section{Introduction}

Platelets have important role in formation of blood clot. These cells are non-nucleated and are produced in bone marrow by megakaryocytes. Their size ranges from 2 to $4 \mu$ mand contain megakaryocyte- derived messenger RNA (mRNA) which is needed for protein synthesis. These cells are devoid of genomic DNA [1]. Normal platelet count ranges from $150,000-450,000$ per $\mu \mathrm{L}$ with mean values of 266,000 and 237,000 per $\mu \mathrm{L}$ in females and males, respectively [2]. About $70 \%$ cells circulate in the blood while $30 \%$ of them remain arrested by the spleen. Its life span ranges from 7-10 days after which these are degraded in the liver or spleen [3].

Decrease in platelet count is termed as thrombocytopenia. Based on severity of decrease, it is subdivided into three groups. Platelet count between 100,000 to 150,000 per $\mu \mathrm{L}$ is classified as mild thrombocytopenia, platelet count between 50,000 to 99,999 per $\mu \mathrm{L}$ as moderate thrombocytopenia and $<50,000$ per $\mu \mathrm{L}$ as severe thrombocytopenia.

Manuscript received: $23^{\text {rd }}$ August 2019

Reviewed: $4^{\text {th }}$ September 2019

Author Corrected: $9^{\text {th }}$ September 2019

Accepted for Publication: 14 ${ }^{\text {th }}$ September 2019
Severe thrombocytopenia has increased risk of bleeding problems. Decrease in platelet count leads to delayed clot formation and prolongation of bleeding time. It can manifest as bleeding in skin and mucous membranes in the form of petechiae, ecchymosis and purpura, epistaxis, gum bleeding, menorrhagia etc [4].

Decrease in platelet count may be caused by decreased production, increased breakdown or trapping of platelets in the spleen. Decreased production of platelets may be due to selective or generalized bone marrow suppression. Viral infections like chickenpox, malignancies like lymphoma, nutritional deficiency of Vit. B12 and folic acid or cytotoxic drugs and toxic chemicals. Increased breakdown is seen in immunological conditions like idiopathic thrombocytopenic purpura, haemolytic uremic syndrome and thrombocytopenia of pregnancy. Increased trapping of platelets in spleen is seen in conditions associated with splenomegaly. Notable conditions are bacterial or parasitic infections, certain malignancies, liver diseases and toxins like vinyl chloride [5]. 


\section{Original Research Article}

Early recognition of degree of thrombocytopenia and its aetiology is helpful in treating the condition in initial stages and preventing the development of complications. More severe and life-threatening bleeding like intracranial haemorrhage can thus be avoided [6].

Aetiology of thrombocytopenia varies from place to place and is dependent upon the locally prevalent infections and environmental exposures. Verma et al found in Varanasi that $14.4 \%$ cases were due to sepsis, $12.9 \%$ due to malaria and $11.9 \%$ due to aplastic anaemia [7] while Paramjit et al observed in Pune that $57.7 \%$ cases were due to malaria and only $0.6 \%$ were due to aplastic anaemia [8].

Few studies have been conducted regarding causation of thrombocytopenia in this area. Hence, the present study was conducted to explore the common causes of thrombocytopenia in this area.

\section{Aims \& objectives}

The present study was conducted to assess the clinical profile and findings of laboratory investigations of patients suffering from thrombocytopenia. It also aimed to find the different causes leading to thrombocytopenia.

\section{Material and Methods}

Study setting: The present study was hospital-based in nature conducted at the department of Pathology, Mata Gujri Memorial Medical College and Lions Seva Kendra Hospital, Kishanganj. The institute is tertiary level health care facility catering to patients from eastern part of Bihar and adjoining parts of West Bengal. Most of the patients are referred ones from nearby health facilities.

Duration and type of study: The present study was cross-sectional in nature conducted between February 2018 to June 2019. Data collection was done between April 2018 to March 2019.

Study subjects: Study subjects included patients admitted in the hospital and in whom thrombocytopenia was detected in routine blood tests.

Inclusion criteria: Patients above 18 years of age and found to be suffering from thrombocytopenia of any degree were included in the present study.

Exclusion criteria: Those patients who did not give consent for the study, those suffering from thrombocytopenia secondary to liver disease, malignancy, chemotherapy or due to drug-induced were excluded from the study. The patients in whom thrombocytopenia was congenital in nature were also excluded from the study.

Sample size calculation: The study conducted by Patne et al showed that thrombocytopenia was caused due to infections in $63.33 \%$ patients [9]. Considering $\mathrm{p}=$ $0.6333, q=0.3667, Z=1.96$ for confidence level of $95 \%$ and $\mathrm{d}$ (absolute precision) $=0.1$, sample size was calculated to be 92 . Considering non-response rate of $10 \%$, final sample size was 102 . Three patients refused to participate in the study and a total of 99 patients were studied.

Sampling methods: Sampling was non-random in nature and the initial 99 patients who fulfilled the selection criteria were included in the present study.

Data collection procedure: Medical Superintendent of the hospital was informed about the purpose and importance of this study and permission was obtained. The patients were selected on the basis of haematological findings from the department of Pathology.

The patients were visited in the wards and consent was taken form them. Detailed socio-demographic and clinical history was obtained. Routine investigations including complete blood count, examination of blood smear, liver function test and renal function test were done.

They were subjected to further investigations like Prothrombin time \& INR, activated partial thromboplastin time, bone marrow aspiration, test for HIV infection, Dengue NSlantigen and Dengue IgM, rK -39 test, Lymph node biopsy, and Ultrasound examination if needed.

Data analysis: Data entry was done in Microsoft Excel 2003 and data analysis was done using Statistical Package for Social Sciences (SPSS) v 16.0. Quantitative data were summarized as mean and SD while qualitative data was expressed in terms of frequency and percentage. Appropriate statistical tests were done when needed.

Ethical consideration \& permission: Permission was obtained from Institutional Ethics Committee for the study. All the study subjects were informed about the study and consent was taken from them. Those who did not give consent were not included. Confidentiality of records was maintained and data was saved safely. 


\section{Original Research Article}

\section{Results}

A total of 99 patients were included in the present study. Age and sex distribution of study subjects as represented in Table-1. It is seen that $34.3 \%$ patients belonged to the age group of $21-30$ years while $31.3 \%$ belonged to the age group of $31-40$ years. $57.6 \%$ of them were males while females constituted another $42.4 \%$.

Table-1: Socio-demographic profile of study subjects.

\begin{tabular}{|c|c|c|}
\hline Characteristics & Frequency (n=99) & Percentage \\
\hline Age (in years) & & $7.1 \%$ \\
\hline$<20$ & 7 & $34.3 \%$ \\
\hline $21-30$ & 31 & $31.3 \%$ \\
\hline $31-40$ & 20 & $20.2 \%$ \\
\hline $41-50$ & 7 & $7.1 \%$ \\
\hline 51 and above & & $57.6 \%$ \\
\hline Sex & 57 & $42.4 \%$ \\
\hline Male & 42 & \\
\hline Female & & \\
\hline
\end{tabular}

Table-2 shows the severity of thrombocytopenia. It was mild $(1,00,000-1,50,000)$ in $24.2 \%$ patients, moderate $(50,000-$ $1,00,000)$ in $52.5 \%$ and severe $(<50,000)$ in $23.2 \%$.

Table-2: Severity of thrombocytopenia.

\begin{tabular}{|c|c|c|}
\hline Platelet count (per cmm.) & Frequency (n=99) & Percentage \\
\hline$<50,000$ & 23 & $23.2 \%$ \\
\hline $50,000-1,00,000$ & 52 & $52.5 \%$ \\
\hline $1,00,000-1,50,000$ & 24 & $24.2 \%$ \\
\hline Total & $\mathbf{9 9}$ & $\mathbf{1 0 0} \%$ \\
\hline
\end{tabular}

Table-3 highlighted the aetiology of thrombocytopenia. In more than half (54.9\%) of the cases, it was infective in origin. Dengue accounted for $31.3 \%$ cases, malaria for $16.2 \%$, enteric fever for $7.1 \%$ and septicaemia for $3 \%$. Megaloblastic anaemia was responsible in $24.2 \%$ cases, thalassemia in $2 \%$, hypersplenism in $6.1 \%$ and chronic liver disease and snake bite each in $2 \%$ cases.

Table-3: Aetiology of thrombocytopenia.

\begin{tabular}{|c|c|c|}
\hline Aetiology & Frequency (n=99) & Percentage \\
\hline Dengue & 31 & $31.3 \%$ \\
\hline Malaria & 16 & $16.2 \%$ \\
\hline Enteric fever & 7 & $7.1 \%$ \\
\hline Septicaemia & 3 & $3 \%$ \\
\hline Megaloblastic anaemia & 24 & $24.2 \%$ \\
\hline Thalassemia & 2 & $2 \%$ \\
\hline Hypersplenism & 6 & $6.1 \%$ \\
\hline Chronic liver disease & 2 & $2 \%$ \\
\hline Snake bite & 2 & $2 \%$ \\
\hline Others & 6 & $6.1 \%$ \\
\hline
\end{tabular}

Table-4 represented the haemorrhagic manifestations in these cases. A total of 39 cases (39.4\%) showed bleeding tendency. Most common site for bleeding was skin and mucous membrane where bleeding manifested in the form of petechiae, purpura and ecchymosis (18.2\%). Gum bleeding was seen in seven cases (7.1\%), vaginal bleeding in four cases (4\%) and epistaxis in three (3\%). Bleeding manifestations were not seen in $60.6 \%$ cases. 


\section{Original Research Article}

Table-4: Haemorrhagic manifestations.

\begin{tabular}{|c|c|c|}
\hline Bleeding site & Frequency & Percentage \\
\hline Skin and mucous membrane & 18 & $18.2 \%$ \\
\hline Gum & 7 & $7.1 \%$ \\
\hline Per vagina & 4 & $4 \%$ \\
\hline Epistaxis & 3 & $3 \%$ \\
\hline Hematemesis & 1 & $1 \%$ \\
\hline Haematuria & 1 & $1 \%$ \\
\hline Others & 3 & $3 \%$ \\
\hline Multiple sites & 2 & $2 \%$ \\
\hline No manifest bleeding & 60 & $60.6 \%$ \\
\hline
\end{tabular}

Table- 5 signified the findings of peripheral smear examination. Anaemia was present in $46.5 \%$ cases, leucopenia in $7.1 \%$ and pancytopenia in $15.2 \%$. Selective thrombocytopenia was seen in $31.3 \%$ cases.

Table-5: Peripheral smear examination.

\begin{tabular}{|c|c|c|}
\hline Peripheral smear & Frequency & Percentage \\
\hline Anaemia & 46 & $46.5 \%$ \\
\hline Leucopenia & 7 & $7.1 \%$ \\
\hline Pancytopenia & 15 & $15.2 \%$ \\
\hline Thrombocytopenia & 31 & $31.3 \%$ \\
\hline Total & $\mathbf{9 9}$ & $\mathbf{1 0 0} \%$ \\
\hline
\end{tabular}

Figure-1 represented the findings of physical examination. Splenomegaly was seen in $16.2 \%$ cases, hepatomegaly in $17.2 \%$ and hepatosplenomegaly in $10.1 \%$.

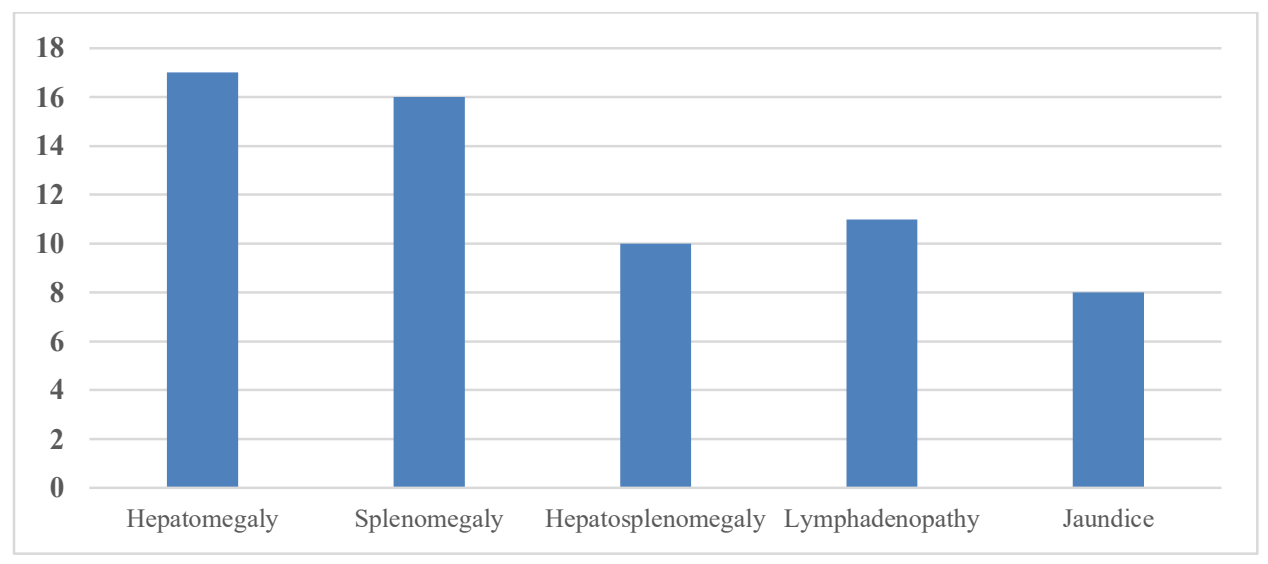

Figure 1: Findings of physical examination

\section{Discussion}

The present cross-sectional study included 99 patients suffering from thrombocytopenia. Male: female ratio of 1.36:1 was observed. Verma et al also found male preponderance with $62.6 \%$ patients being male. Similar findings were observed by Shah et al (male-54\%) [10], Vimal et al (59.2\%) [11], Mittra et al (70.3\%) [12], Paramjit et al (68\%) [8] and Patne et al (60\%) [9]. Majority of the patients $(65.6 \%)$ belonged to the age group of 21-40 years. Verma et al observed that $40.8 \%$ were of the patients belonged to the age group 26-50
[7]. Shah et al found highest incidence of thrombocytopenia in the age group 21-30 years (30\%) [10]. Paramjit et al also found that $52.3 \%$ cases were in the age group 20-39 years [8]. However, Vimal et al had slightly different observation who reported that most of the cases belonged to the age group 41-60 years (37.4\%), followed by $21-40$ years $(33.4 \%)$ which was observed in southern part of India [11]. Moderate thrombocytopenia was seen in about half of the patients $(52.5 \%)$ while the condition was severe in $23.2 \%$. 


\section{Original Research Article}

Verma et al reported that mild thrombocytopenia was present in $41.2 \%$, moderate in $34.9 \%$ and severe in $23.9 \%$ [7]. Vimal et al reported that majority of the patients $(54.2 \%)$ presented with a platelet count between 50,000-1,00,000 and $25.8 \%$ presented with a platelet count between $1,00,000$ to $1,50,000$ similar to the findings of the present study [11]. However, Mittra et al found that mild thrombocytopenia was present in $22.2 \%$, moderate in $33.3 \%$ and severe in $44.4 \%$ [12]

In more than half $(54.9 \%)$ of the cases, it was infective in origin. Dengue accounted for $31.3 \%$ cases, malaria for $16.2 \%$, enteric fever for $7.1 \%$ and septicaemia for $3 \%$. Megaloblastic anaemia was responsible in $24.2 \%$ cases, thalassemia in $2 \%$, hypersplenism in $6.1 \%$ and chronic liver disease and snake bite each in $2 \%$ cases.

Verma et al explored causes of thrombocytopenia in detail and reported that common causes of thrombocytopenia in their setting were sepsis in $14.4 \%$, CLD in $12.9 \%$, malaria in $12.2 \%$, aplastic anemia in $11.9 \%$ and viral illness in $9.9 \%$. Patients, whose platelet counts returned to normal within 6 weeks follow-up, were classified as acute and whose not, classified as chronic.

Causes of acute thrombocytopenia include megaloblastic anemia, sepsis, malaria, typhoid fever, dengue and other viral illness. Out of which most common cause was sepsis $(28.6 \%)$ followed by malaria (24.4\%). Causes of persistent (chronic) thrombocytopenia were aplastic anemia, myelodysplastic syndrome (MDS), hypersplenism, hematological malignancies and chronic liver disease.

Most common cause was chronic liver disease (25.3\%) followed by aplastic anemia (23.3\%) [7]. Shah et al reported that the most common cause of thrombocytopenia was malaria (31\%) followed by Megaloblastic anemia (26\%) and dengue fever (18\%) [10].

The etiological diagnosis of patients in South India was reported by Vimal et al as Dengue (21.67\%), Malaria (6.7\%), Enteric fever (5.9\%), Septicemia (5\%), Chronic liver disease (16.7\%), Chronic kidney disease (3.4\%), Diabetes $(7.7 \%)$, Malignancy $(1.67 \%)$, Coronary artery disease $(3.4 \%)$, Pregnancy $(5 \%)$ Hematological disorders (18.4\%) and miscellaneous (5\%) [11].

Paramjit et al observed in Pune that Infectious etiology was the most important cause, with malaria (57.7\%) being the principal reason. Other common causes included dengue $(27.7 \%)$, liver disease $(7.7 \%)$, and sepsis $(4.7 \%)$ [8].
It is evident from the above discussion that common causes of thrombocytopenia are related to locally prevalent infections and disease patterns. In areas with Malaria and Dengue, these constitute important causes. In other areas, other infections and chronic conditions are mainly responsible.

A total of 39 cases (39.4\%) showed bleeding tendency. Most common site for bleeding was skin and mucous membrane where bleeding manifested in the form of petechiae, purpura and ecchymosis (.2\%). Gum bleeding was seen in seven cases $(17.9 \%)$, vaginal bleeding in four cases (4\%) and epistaxis in three (3\%). Bleeding manifestations were not seen in $60.6 \%$ cases. Verma et al also found that skin manifestations in the form of petechiae, ecchymosis were most common bleeding manifestation and was seen in $13 \%$ patients. Gum oozing and epistaxis was present in $8.6 \%$ of cases.

Patients complaining of acute onset blurred vision were examined with direct ophthalmoscope to look for fundal bleed which was present in 5.6\%. Active gastrointestinal bleed and vaginal bleed was present in $7 \%$ and $2.4 \%$ cases and required urgent platelet transfusion [7].

Shah et al also had similar observation who commented that most common bleeding manifestation was in skin and mucous membrane (33\%) followed by gum bleeding (25\%) and bleeding per vagina (19\%). The major clinical bleeding in the form of intracranial hemorrhage was detected in only one patient $(3 \%)$. ITP (42\%) and dengue fever (33\%) were common etiologies associated with skin and mucous membrane bleeding. In patients with gum bleeding, dengue fever (33\%) and Megaloblastic anemia (33\%) were common causes, while in patients with per vaginal bleeding, ITP (58\%) was the common etiology [10].

Anaemia was present in $46.5 \%$ cases, leucopenia in $7.1 \%$ and pancytopenia in $15.2 \%$. Selective thrombocytopenia was seen in $31.3 \%$ cases. Verma et al reported that isolated thrombocytopenia, thrombocytopenia with anemia, thrombocytopenia with leucopenia and pancytopenia was present in $29.1 \%$, $37.1 \%, 31.2 \%$ and $2.5 \%$ patients respectively.

Macrocytic anemia was present in megaloblastic anemia and in all other cases, it was mainly normocytic normochromic type. Anemia is an important accompaniment of thrombocytopenia. In all the patients with pallor and having high risk of thrombocytopenia, platelet count must be done to rule out this condition [7]. Splenomegaly was seen in $16.2 \%$ cases, hepatomegaly in $17.2 \%$ and hepatosplenomegaly in 


\section{Original Research Article}

$10.1 \%$. Shah et al have concluded that splenomegaly was found in $1 / 4^{\text {th }}$ of patients with thrombocytopenia.

While splenomegaly as a part of Hypersplenism itself causes thrombocytopenia, many diseases like malaria, enteric fever etc. are associated with Splenomegaly. Most common cause of splenomegaly was malaria (56\%) followed by cirrhosis of liver (24\%) [10].

Vimal et al was of opinion that thrombocytopenia can occur as a combined or isolated finding in many hematological conditions like megaloblastic anemia, aplastic anemia and hypersplenism. Iron deficiency anemia is commonly associated with reactive thrombocytosis, but thrombocytopenia can occur in severe cases [11].

\section{Conclusion}

It might be concluded from the present study that thrombocytopenia was more common in males and in the age group of 21-30 years. Bleeding was seen in $39.4 \%$ cases mainly in skin and mucous membranes. About half of the patients had moderate to severe thrombocytopenia. About half of the cases had thrombocytopenia due to infective reasons. Early identification and timely treatment can help in proper management of cases.

\section{What the study adds to the existing knowledge?}

Literature regarding pattern and aetiology of thrombocytopenia are limited in number. Majority of the cases are infective in origin. As thrombocytopenia is a commonly encountered condition with probability of severe consequences, the present study gives insight to common causes of thrombocytopenia in this area as well as the profile of cases in terms of severity and clinical findings. This will help in ensuring timely interventions for preventable conditions and reduction in morbidity and mortality.

\section{Author's contribution}

- Dr. Ajay Kumar: Designed the study and collected data.

- Dr. Avinash Priyadarshi: Design of study protocol and ensured proper methodology for scientific soundness.

- Dr. Sanjay Kumar: Guided the research work as the senior-most member of the team.

- Dr. Prabhat Kumar Lal: Data analysis and review of literature.

Findings: Nil; Conflict of Interest: None initiated Permission from IRB: Yes

\section{References}

1. Morrell CN, Aggrey AA, Chapman LM, Modjeski KL. Emerging roles for platelets as immune and inflammatory cells. Blood. 2014; 123 (18): 27592767. doi:10.1182/blood-2013-11-462432. Epub 2014

Feb 28.

2. Buckley MF, James JW, Brown DE, Whyte GS, Dean MG, Chesterman CN, et al. A novel approach to the assessment of variations in the human platelet count. Thromb Haemost. 2000;83(3):480-484.

3. Gresele P, Harrison P, Bury L, Falcinelli E, Gachet C, Hayward CP, et al. Diagnosis of suspected inherited platelet function disorders: results of a worldwide survey. J Thromb Haemost. 2014;12(9):1562-1569. doi: 10.1111/jth.12650. Epub 2014 Jul 25.

4. Williamson DR, Albert M, Heels-Ansdell D, Arnold DM, Lauzier F, Zarychanski R, et al. Thrombocytopenia in critically ill patients receiving thromboprophylaxis: frequency, risk factors, and outcomes. Chest. 2013;144(4):1207-1215. doi: 10.1378/chest.130121. DOI:10.1378/chest.13-0121

5. Chaudhary B, Jyothi Y, Rabbani SI. Thrombocytopenia and its causes. J Chemical Pharma Res. 2016;8 (2):184-189.

6. Veneri D, Franchini M, Randon F, Nichele I, Pizzolo G, Ambrosetti A. Thrombocytopenias: a clinical point of view. Blood Transfus. 2009;7 (2):75-85. doi: $10.2450 / 2008.0012-08$.

7. Verma S, Meena LP, Rai M. Clinical and etiological profile of patients with thrombocytopenia at tertiary care centre in north eastern part of India. Sepsis. 2019; 8(3): 437-442.

8. Paramjit E, Rao R, Sudhamani S, Roplekar P, Shaffi Z, Roy S. Spectrum of thrombocytopenia: A clinicopathological study with review of the literature. Muller J Med Sci Res. 2016;7(2):121-124. doi: 10. 4103/09759727.185012

9. Patne SV, Chintale KN. Clinical profile of patients with thrombocytopenia at tertiary health care centre. Int J Adv Med. 2017;4(6):1551-1556. doi.org/10.18203 /2349-3933.ijam20175082

10. Shah HR, Vaghani BD, Gohel P, Virani BK. Clinical profile review of patients with thrombocytopenia: a study of 100 cases at a tertiary care centre. Int J Curr Res Rev. 2015;7(6):33-37. 


\section{Original Research Article}

11. Vimal M, Parveen S. Clinico pathological profile of spectrum of thrombocytopenic cases - a cross sectional study. Trop J Path Micro 2016;2(3): 146-151.doi: 10.17511/jopm. 2016.i3.11.

12. Mittra P, Pandey MK. Clinicopathological Profile of Thrombocytopenia in Sitapur and Shahjahanpur Districts of Uttar Pradesh. Int J Contemp Med Res. 2019;6(1): A25-A27. doi: http://dx.doi.org/10.21276 /ijcmr.2019.6.1.40

\section{How to cite this article?}

Kumar A., Priyadarshi A., Kumar S. ${ }^{3}$, Kumar L.P. ${ }^{4}$ Observational study on clinicopathological profile of thrombocytopenia cases in a medical college hospital. Trop J Path Micro 2019;5(9):696702.doi:10.17511/jopm.2019.i09.13. 